\title{
Changing Course: Exploring Impacts Of Waiting For Superman On Future Teachers' Perspectives On The State Of Education
}

Aaron Jensen, University of Wyoming, Graduate Student, USA Edward Janak, Ph.D., University of Wyoming, USA

Timothy F. Slater, Ph.D., University of Wyoming, USA

\begin{abstract}
The controversial video documentary Waiting for Superman, released in 2010, has helped to ignite a firestorm of national debate on current educational reforms in the United States. The purpose of this study is to determine the possible impacts of the video documentary Waiting for Superman potentially influencing pre-service education teachers' attitudes about education and current educational practices. Twenty-seven pre-service, post baccalaureate, teacher-education students volunteered for this exploratory study which used pre/post surveys and a focus group of six randomly chosen volunteers from the participants to determine what, if any, impact Waiting for Superman had on their view on current educational issues. This data suggests that Waiting for Superman altered students' pre-existing notions about teachers' unions, the importance of effective teachers, and enhanced their outlook on charter schools over public schools. This study contributes to our growing understanding of how widely disseminated video documentaries can influence attitudes about educational practices among future teachers so as to guide teacher education programs about the possible inclusion of such videos as part of the undergraduate curriculum.
\end{abstract}

Keywords: Teacher Education; Waiting for Superman; Affective Domain

\section{INTRODUCTION}

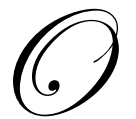

n October 8, 2010 Paramount Pictures released the video documentary Waiting for Superman (IMDb, 2011). Within months public reactions to this film were being used as a catalyst to develop a new education reform movement and supporting organization called DoneWaiting.org. (WaitingforSuperman.com, 2010). Both the movie and the organization have the support of major educational donors such as the Doris \& Donald Fisher Fund, The Bill \& Melinda Gates Foundation, The Ford Foundation, and the United Way (Weber, 2010). In its wake, Waiting for Superman has become a talking point demonstrating the disparities that exist in our current educational system and suggests ways to improve those disparities. Waiting for Superman has become a significant face for organizations wishing to transform education in the United States. Eric Schwarz, the cofounder and CEO of Citizen Schools, advocates that concerned citizens should show the documentary at home or in their community and begin talking about it with school boards and legislators (Weber, 2010). The book's website even provides talking points and conversation topics to discuss afterword (WaitingforSuperman.com, 2011). For our present concerns, professors at Colleges of Education across the country, who are charged with preparing future teachers, would benefit if they knew, "would this video be an effective tool at preparing the next generation of teachers?" It is to this end that this study is directed.

\section{BRIEF OVERVIEW OF WFS}

In brief, Waiting for Superman (WFS), by the filmmaker Davis Guggenheim, pokes at the success of the contemporary American public school system and explores ways that it is failing our nations' children. Davis 
Guggenheim is perhaps most well-known for his work on the global climate change film featuring $\mathrm{Al}$ Gore, $A n$ Inconvenient Truth, described below. During the WFS film, Guggenheim follows five students who want "a good education" and whose parents decide to look for it by exploring charter school options outside of public schooling. Each of the families decided to try and enroll their children in a charter school, hoping that it will provide a better pathway for their students to succeed in life. However, as Guggenheim shows, the shortage of admission opportunities for good charter schools requires each of the five families to enter a lottery to see if they are lucky enough to be admitted to what they feel are superior schools.

A main thesis of the film is that American students should not have to be "lucky" to attend superior schools. Throughout the film Guggenheim discusses some of the issues that, he feels, are at the core of the struggling American school system. Much of his focus is centered on teachers' unions and how they protect and support continued employment of "bad" teachers. He challenges that unions are too worried about keeping teachers in their jobs regardless of the effectiveness of that teacher. He offers that protection of ineffective teachers weakens our system and does a disservice to our students. He isn't alone in this perspective. In a recent Atlantic Monthly interview, teachers' union leader Albert Shanker states that, "When schoolchildren start paying union dues, that's when I'll start representing the interests of schoolchildren"(Klien 2011).

Throughout WFS, nationally recognized education reformers, including Michelle Rhee, the former chancellor of the Washington D.C. public school system; Geoffrey Canada, CEO of the Harlem Children's Zone; and Eric Hanushek, a professor at Stanford University, highlight examples of how our current school system is failing to help students become productive members of society. Of particular emphasis are the perhaps surprisingly low graduation rates endemic to particular minority groups. Many of these ideas are outlined and formally cited elsewhere by Weber (2010). The highlighted reformers use their own experiences in the school system and at alternatives to public schooling to show that the tools to improve our schools exist today, are not expensive, and can create an environment where our students can learn.

As but one illustrative example, Stanford's Eric Hanushek (2010) aggressively argues that great teachers, defined as those who consistently and significantly increase student-performance, are able to overcome the wellestablished average achievement deficit between low socio-economic status (SES) students and others. He goes on to argue that low SES students rarely get consecutive years of such great teachers because $15.1 \%$ of the teachers leave low SES serving schools every year. In Weber (2010, p. 24), Hanushek is quoted as boldly suggesting, "If in fact we could just eliminate the bottom 6 to 10 percent of our teachers and replace them with an average teacher, we could bring the average U.S. student up to the level of Finland, which is at the top of the world today." One naturally wonders the extent to which such seemingly sensible revelations can impact the thinking of future teachers currently in the educator-preparation pipeline?

\section{EDUCATIONAL CRITICISM AND THE ROLE OF DOCUMENTARIES}

Starting in the late 1800's, the general public had a deep respect of their public schools. Advocates such as Horace Mann put forth rhetoric about the public schools being the cure-all for the United States. For example, in the "Conclusion of Introduction" in the January 1841 Common School Journal he explained:

...the common school is the greatest discovery ever made by man...Let the Common School be expanded to its capabilities, let it be worked with the efficiency of which it is susceptible, and nine-tenths of the crime in the penal code would become obsolete; the long catalog of human ills would be abridged; men would walk more safely by day; every pillow would be more inviolable by night; property, life, and character held by a stronger tenure; all rational hopes respecting the future brightened (15).

The force of Mann's rhetoric rang true in the ears of most Americans, leading to a surge in support of, and faith in, the common schools (public schools). As new social ills arose, the US turned its eyes to the schools as a means of dealing with these challenges. Accordingly, the purpose of the public schools has grown throughout history; in addition to a pure academic purpose, the public schools have come to take religious (teaching character and morals), political (producing an educated electorate), social (assimilating various groups into "good Americans"), and economic (keeping kids off the streets so adults can hold jobs and training children in vocational arts) purposes. For almost 50 years, most Americans believed the public school system was doing its job. 
However, in the latter half of the Twentieth Century, American faith in its public schools was shaken. Arguably it was part of the post-Watergate zeitgeist of the nation, Americans in the late 1970's wandered around questioning everything. Capturing this spirit was Rudolph Flesch, an Austrian-born writer on the use and teaching of language. He had been producing texts on better ways to teach reading since the 1950's, but it was his 1981 text Why Johnny Still Can't Read-A New Look at the Scandal of Our Schools that captured the nations' attention. Suddenly the news was filled with stories about the perceived failures of the public schools, and the general public began demanding somebody do something about it.

1983 marked the year the media captured the nation's attention about a perceived crisis in the public schools. The report published by the federal government, A Nation at Risk, fundamentally altered the national conversation regarding schooling in two substantive ways. First, it was the clearest expression of American lost faith in its public schools. If they were the "greatest invention ever" according to Horace Mann, now they were a source of national shame. The report linked educational success with national success, this time in militaristic terms. It's opening paragraph read, in part:

Our nation is at risk. Our once unchallenged preeminence in commerce, industry, science, and technological innovation is being overtaken by competitors throughout the world...the educational foundations of our society are presently being eroded by a rising tide of mediocrity that threatens our very future as a Nation and a people...If an unfriendly foreign power had attempted to impose on America the mediocre educational performance that exists today, we might well have viewed it an act of war. As it stands we have allowed this to happen to ourselves...We have in effect been committing an act of unthinking, unilateral educational disarmament (Anonymous, 1)

With rhetoric like that ringing in their ears, most Americans were all too happy to put aside any conversation regarding an esoteric purpose of schooling, including schooling as a means of perpetuating and preserving the republic, let alone building good citizens to improve society. The second way this report fundamentally altered the national conversation was by ushering in a neoliberal period of educational control. More and more the American public was calling for federal oversight of its schools. This led to a series of progressively more intrusive acts, beginning with America 2000 and Goals 2000 and ultimately leading up to No Child Left Behind.

However, as federal intervention in education continued to rise in ascendancy, so too did the public's calls for accountability and transparency. The more the government got involved in the schools, the more the public wanted to know what was happening as a result of this intervention. The media were happy to oblige with books, articles, and more recently websites and blogs. All of this new-found attention, most of it negative, led to an interesting paradox in public opinion: while Americans were mistrustful of public schools as an institution, they still had great faith in their local schools. As detailed in a 2011 Education Next survey (p.1), only 3\% of Americans graded public schools with an "A" and $19 \%$ with a "B", with $19 \%$ assigning a "D" and $6 \%$ an "F". However, when asked to grade the schools in their communities, $10 \%$ of Americans graded public schools with an "A", $36 \%$ a "B", $13 \%$ assigning a " $\mathrm{D}$ " and 5\% an " $\mathrm{F}$ ". Clearly there is a disconnect between what Americans think when they see something with their own eyes (i.e. their local schools) and what they think when they are told about something by the media (i.e. public schools).

As with education there has been a great deal of research on how media affects societies. As an example, Kellner (1995) studied the effects of media on society focusing on content and meaning of the media:

A media culture has emerged in which images, sounds, and spectacles help produce the fabric of everyday life, dominating leisure time, shaping political views and social behavior, and providing the materials out of which people forge their very identities (p. 1)

It seems that media has the ability to influence society at a very fundamental level, including morals and perceptions of the world. It influences what citizens perceive as reality, and affects thoughts, feelings, and actions (Temple, 2009). Because media in general, but films specifically, impact on such a wide level they can be a very compelling medium for learning (Temple, 2009). Barnett and his Colleagues (2006) evaluated the use of a science fiction film The Core for an environmental science unit of an eighth grade class. At the end of an 8-week unit 
involving engaging hands-on projects, there was a tendency among students to explain the concepts taught using the film rather than the class lessons. This particular science fiction film was wildly inaccurate and incorrectly explained concepts that students learned in class, yet had a greater impact on student learning than did eight weeks of projects. Barnett highlights one student who noted that the projects were her favorite part of the unit but still used examples from the film to explain a relevant concept (Barnett, et al., 2006)

Although it is generally agreed that fiction films have a great ability to communicate with their viewers, documentaries have the potential to be equally, if not more, powerful. Documentaries intentionally portray the world by making it seem familiar, through representing multiple interests and providing information to back up a certain perspective, similar to the way a lawyer gives evidence (Nichols, 2001, p. 2-3). Those viewing a documentary made in this style may accept the information as trustworthy and " $[\mathrm{w}]$ hen we believe what we see bears witness to the way the world is, it can format he basis for our orientation to or action within the world"(Nichols, 2001, p.2-3). Because of these facts many documentaries have become a "call to action"-- a push to change the status quo.

Davis Guggenheim, the director of Waiting for Superman, has had experience in creating media presentations intended to bring people to action. One example is his film An Inconvenient Truth. Several studies involving An Inconvenient Truth (AIT) have tried to judge its efficacy at getting people to act. Grant Jacobsen (2009) studied how AIT corresponded with voluntary carbon offsets purchased. While this film was in theaters there was a 50\% increase in the amount of voluntary Carbon-fund carbon offsets purchased within 10 miles of the theater (Jacobsen, 2009). However, this film did not seem to cause long-term change in this regard as those increased sales only lasted for one year (Jacobsen, 2009). Jessica Nolan (2009) used surveys to explore how effectively AIT changed belief and understanding of environmental concepts and whether or not those beliefs turned into action. Students and community members who saw An Inconvenient Truth were shown to have increased understanding of the topic and a desire to change their lives to create more sustainable living (Nolan, 2010). After a month many people maintained a high concern for environmental problems facing the Earth; however, there were very few individuals who actually followed through on their plans to change their lives (Nolan, 2010). Taken together, these illustrative studies suggest that the immediate impact of films can be intense and, even though the impact may not lead to action, it could potentially lead to a long term shift in the way individuals perceive the world around them.

\section{PRESENT STUDY: IMPACT OF WFS}

The purpose of the present study is to measure the impact of WFS in terms of how it affects future teachers' attitudes and beliefs about our current educational system. Based on previous research on media and learning, it seems plausible that pre-service teachers will demonstrate a shift in their beliefs about education based on what is presented in the film. Alternatively, it seems equally plausible that the formal collegiate coursework inherent to the preparation of future teachers may insulate them from potential impacts of such a film. It is to this end that the current study is directed.

\section{Participants}

Participants for this study were solicited from a post baccalaureate educational methods class taught in the summer of 2011 at a small, Rocky Mountain region, doctoral-granting, research intensive University. The documentary was shown as a regular portion of an educational foundations course however; participation in the survey was voluntary. In all 27 students participated in the study. Six students were chosen at random from the volunteers to participate in a focus group three days after watching the documentary. The ages of participants ranged from 22 to 39 with an average age of $27(\mathrm{sd}=3.9)$. There were 16 females and 11 males in the study. 26 of the 27 participants were post baccalaureate students. Science was the most common major of the participants with 11 students studying in that area. Of the remaining 16 students, nine were non-science secondary majors, five were elementary majors, and one declined to comment.

\section{Research Design}

After an approved human subjects consenting process, volunteer participants were asked to fill out two short surveys, one before watching Waiting for Superman and another immediately afterwards. After the second 
survey students were asked to volunteer for a focus group interview that would take place three days later. Six participants were randomly chosen from those interested to participate in the focus group.

Participant
Solicitation $\Rightarrow \begin{aligned} & \text { Pre- } \\ & \text { Video } \\ & \text { Survey }\end{aligned} \Rightarrow \begin{aligned} & \text { Video } \\ & \text { Intervention }\end{aligned} \quad \Rightarrow \begin{aligned} & \text { Post- } \\ & \text { Video } \\ & \text { Survey }\end{aligned} \Rightarrow \begin{aligned} & \text { Class } \\ & \text { Debriefing }\end{aligned} \Rightarrow \begin{aligned} & \text { Focus } \\ & \text { Interview }\end{aligned}$

\section{Measures}

Participants completed a 27 -item survey that included measures on topics that were relevant to the documentary. The survey used 25 questions on a variety of topics including: teachers' unions, effectiveness of public schools, effectiveness of charter schools, school choice, and teacher validity. The survey questions used a four point Likert scale to gauge student beliefs. These questions were evaluated using the Wilcoxon signed-rank test. The last two questions on the survey were opened ended, short answer questions asking students to state some of the greatest challenges facing education today and the best ways to face those challenges. The survey is included in the Appendix.

\section{Survey Results}

Summarized in Table 1, the results of the pre/posttest survey showed that there was significant change in the attitudes and beliefs of these post-baccalaureate, pre-service teachers as a result of viewing this documentary. Analysis of the six targeted items regarding attitudes and beliefs toward teachers' unions showed that in all questions students had a significantly lower opinion of unions after watching Waiting for Superman than they did before. Questions regarding public schools were split with three showing significant decreases and three showing no change in opinion. When asked if schools were doing a good job preparing students for their future the average pre-survey score was relatively high (3.0 out of 4), but dropped (mean of $2.5, \mathrm{p}=.005$ ) after seeing the film. Interestingly, but similarly to the national public opinion statistics quoted previously in this article, students' opinion of public schools in their own state (all participants were from the same low-population, Rocky Mountain-region state) did not drop significantly (mean of 3.1 to 2.9) after seeing the film. The same was true when asking about the ability to think and act creatively and high standards in public schools. It should be noted that both of those questions began fairly low on the scale (mean of 2.2 or less) and one might be seeing a limit to how low they could go.

While future teachers' opinions about public schooling declined, watching the film dramatically enhanced their opinions on charter schools. The results of the pre-survey show that participants felt that charter schools were equivalent to public schools in almost every measure. Post-survey results show that many participants felt that charter schools were better if not equal to public schools in their ability to prepare students for their future and expected standards.

On the pre-survey students felt that teachers were not paid enough. That number significantly increased $(\mathrm{p}=.035)$ on the post-survey. On the pre-survey many students felt that there were many non-monetary rewards for teaching, that number significantly dropped $(\mathrm{p}=.015)$ on the post-survey. When asked on the pre-survey what the major problems facing education today, a majority (10 of 18 respondents) felt that lack of funding was a major issue. Other common educational issues were more freedom for teachers and less bureaucracy. The post-survey showed that $67 \%$ of respondents felt that teachers' unions and ineffective teachers were the most pressing problems facing education today.

\section{Focus Group Results}

The purpose of the focus group was to better understand some of the general feelings pre- service teachers had about Waiting for Superman and to clarify their thinking about the questions that were on the survey and why they chose particular answers. Perhaps surprisingly, analyses of the focus group interview results were dramatically different than that of the surveys, described above. Overall students were not that impressed with Waiting for Superman, and stated that it had very little effect upon them and how they view education. Many students pointed 
out that there was some very obvious bias in the film as 4 of the 5 students were minorities and all of them were attending large urban schools. The participants saw the problems presented in the documentary as "big city" problems occurring far from the rural, Rocky Mountain state in which this interview was occurring, and that they could not relate well with the stories. When asked about opinions in the film they agreed with several participants and restated that the film was biased and was probably not giving a complete story.

Because these comments were so dramatically different than the survey results, the focus group interviewer asked more targeted questions addressing specific topics such as unions. When asked for specific examples, participants began to soften in their opposition to the film. One stated that they did not have much experience with unions, but if that is what unions are doing then it needs to stop. Several participants felt that to role of unions needs to change to focus energy on students and learning. The clear consensus of the group was that ineffective teachers need to be fired and that the process of firing needs to be made simpler. When talking about charter and public schools the majority of participants felt that "good" charter schools are great and that educational practices learned there should be more widely implemented. However, many felt that not all charter schools are automatically to be considered "good" and pointed out that "bad" charter schools are probably no better than "bad" public schools. By the end of the focus group interview, participants unanimously agreed that it was good for them to watch the film, not because it changed them but because it gives them an idea of what they may have to work with in the future.

\section{DISCUSSION}

In summary, the data collected in this study suggest that Waiting for Superman does seem to influence the attitudes of those future teachers who see it. As predicted there was a significant change in student beliefs on the topics addressed in this film, mainly teachers unions, public and charter schools, and teacher viability. The strongest changes deal with unions and ineffective teachers. In this instance previous research on An Inconvenient Truth holds true in that students shifted their belief system.

On first glance, there seemed to be some disconnect between the results from the survey and short answer and the focus group. The significant shifts in beliefs observed in the survey data did not seem to coincide with focus group participants who felt strongly that the film was biased and not telling the whole truth. In this case, "history" was a significant threat to this study's overall validity. Further study into what may have happened between the end of the film and the interview revealed that the professor of the participating class was asked several questions about the film after taking the post-survey but before the focus group occurred. The professor's responses to these questions, where he was dismissive of the film's claims seems to be the most logical explanation as to how all six focus group participants suddenly seemed hostile to the film. This experience seems to directly contradict the results by Barnett and colleagues, cited earlier, where students were more likely to rely on a science fiction film to explain concepts than the projects they had worked on for 8 weeks in their classroom. However, interview participants, while outright rejecting parts of Waiting for Superman, seemed to accept the information on unions, teachers, and the condition of urban schools. This piece-meal acceptance of some facets while ignoring others is interpreted to suggest that while the film had an effect of the students' beliefs their professor had a greater effect. Alternatively, it is plausible that student attitudes and beliefs about these ideas are easily malleable.

These results urge us to conduct deeper studies into understanding what future teachers' preconceptions are based upon and to conduct a longer duration study to ascertain how much "sticking power" films such as WFS have for future teachers. This study suggests that Waiting for Superman and other media like it can have a powerful effect on the beliefs of pre-service teachers; however, that effect may not supersede the impact of their professors. Further, these results strongly suggest that a study on the longevity and malleability of future teachers' beliefs fostered through media are warranted.

\section{AUTHOR INFORMATION}

Aaron Jensen is currently a Ph.D. graduate student at the University of Wyoming. He earned his Masters Degree in the Integration of technology into classrooms through Walden University. He taught middle school science for nine years in Oregon. E-mail: ajensen1@uwyo.edu. Corresponding author. 
Edward Janak, Ph.D., teaches in the Department of Educational Studies, University of Wyoming, after having earned his Ph.D. in the Social and Historical Foundations of Education while simultaneously teaching high school in South Carolina. In addition to memberships in the History of Education Association, American Educational Studies Association, International Society of Educational Biography, and Kappa Delta Pi, Dr. Janak serves as the "Teaching, History, Education and Pop Culture" area chair of the Pop Culture/American Culture Association. His work in foundations and education biography has appeared in journals such as Vitae Scholasticae, Educational Studies, and the Journal of Popular Culture. E-mail: ejanak@uwyo.edu

Timothy F. Slater, Ph.D., is the University of Wyoming Excellence in Higher Education Endowed Chair of Science Education and a Professor in the College of Education and the Department of Physics. He is the Director of the CAPER Center for Astronomy \& Physics Education Research, a multi-institutional virtual collaborative of scholars studying cognition and learning of undergraduates, with a particular emphasis on understanding the effective preparation of future science teachers. He has been a member of the Board of Directors of the National Science Teachers Association, the Astronomical Society of the Pacific, and the American Astronomical Society. E-mail: tslater@uwyo.edu

\section{REFERENCES}

1. $\quad$ Anonymous. (1984). A nation at risk. Washington, D.C.: U.S.A. Research.

2. $\quad$ Barnett, M., Wagner, H., Gatling, A., Anderson, J., Houle, M., \& Kafka, A. (2006). The impact of science fiction film on student understanding of science. Journal of Science Education and Technology, 15(2), 17991.

3. Howell, W. et al. (2011). "Education Next-PEPG Survey of Public Opinion.” EducationNext.org. Retrieved November 16, 2011 from http://educationnext.org/files/ENPEPG_Complete_Polling_Results_2011.pdf

4. IMdB. (2011). Internet Movie Data Base. Retrieved from http://www.imdb.com/title/ tt1566648/

5. Guggenheim, D. (2010). Waiting for Superman [Motion Picture]. United States: Paramount Pictures.

6. Hanushek, E. (2010). The difference is great teachers. In Waiting for superman: How we can save American's failing public schools (Weber, K., Ed.). PublicAffairs/Perseus Books Group: New York. (page 4)

7. Jacobsen, G. (2011). The Al Gore effect: An Inconvenient Truth and voluntary carbon offsets. Journal of Environmental Economics and Management, 61(1), 67. Retrieved October 14, 2011, from ABI/INFORM Global. (Document ID: 2238866301).

8. $\quad$ Kellner, D. (1995). Media culture. London: Routledge.

9. $\quad$ Mann, H. (January 1841). Introduction. Common School Journal, 3, 1. 1-16.

10. Nichols, B. (2001). Introduction to documentary. Bloomington: Indiana University Press.

11. Nolan, J. (2010). "An Inconvenient Truth" Increases Knowledge, Concern, and Willingness to Reduce Greenhouse Gases. Environment and Behavior, 42(5), 643. Retrieved October 14, 2011, from Research Library. (Document ID: 2139339201).

12. Temple, L. (2009). An exploration of the role of film in environmental education. M.E.S. dissertation, Dalhousie University (Canada), Canada. Retrieved October 14, 2011, from Dissertations \& Theses: Full Text. (Publication No.AAT MR56360).

13. Waiting for superman.com. (2010). Retrieved from. http://www.waitingforsuperman.com/ action/

14. Weber, K. (2010). Waiting for superman: How we can save American's failing public schools. PublicAffairs/Perseus Books Group: New York. (page 4)

15. Klein, Joel. (June 2011). The failure of American schools. The Atlantic. Retrieved from http://www.theatlantic.com/magazine/archive/2011/06/ the-failure-of-american-schools/8497/1/ 


\section{APPENDIX}

Waiting For Superman Survey and Results

1= Strongly Disagree 2= Disagree 3=Agree 4= Strongly Agree

\section{Questions}

Overall across the nation, public schools adequately prepare students to be contributing members of society

Overall across Wyoming, public schools adequately prepare students to be contributing members of society

Nationally, public schools overall foster an atmosphere of creativity and educational freedom for both teachers and students.

There are enough charter schools to meet demand across the country.

Most students leave public schools ready to enter the workforce or go to college.

The ability for families to select the school of their own choosing undermines the public school system.

Charter schools do a better job than public schools in preparing students to be contributing members of society.

Teacher unions benefit both teachers and students.

Overall, public schools are not adequately preparing students. Public schools do not adequately recognize the difference between good and bad teachers.

Teachers unions make it too difficult to remove or fire ineffective teachers

Teacher unions sufficiently encourage educational reform. The ability to choose your own school would encourage failing schools to improve.

Failing charter schools are sufficient proof that the current system effectively regulates them. Teacher unions positively impact public school education.

Charter schools foster more of an atmosphere of creativity and educational freedom for both teachers and students.

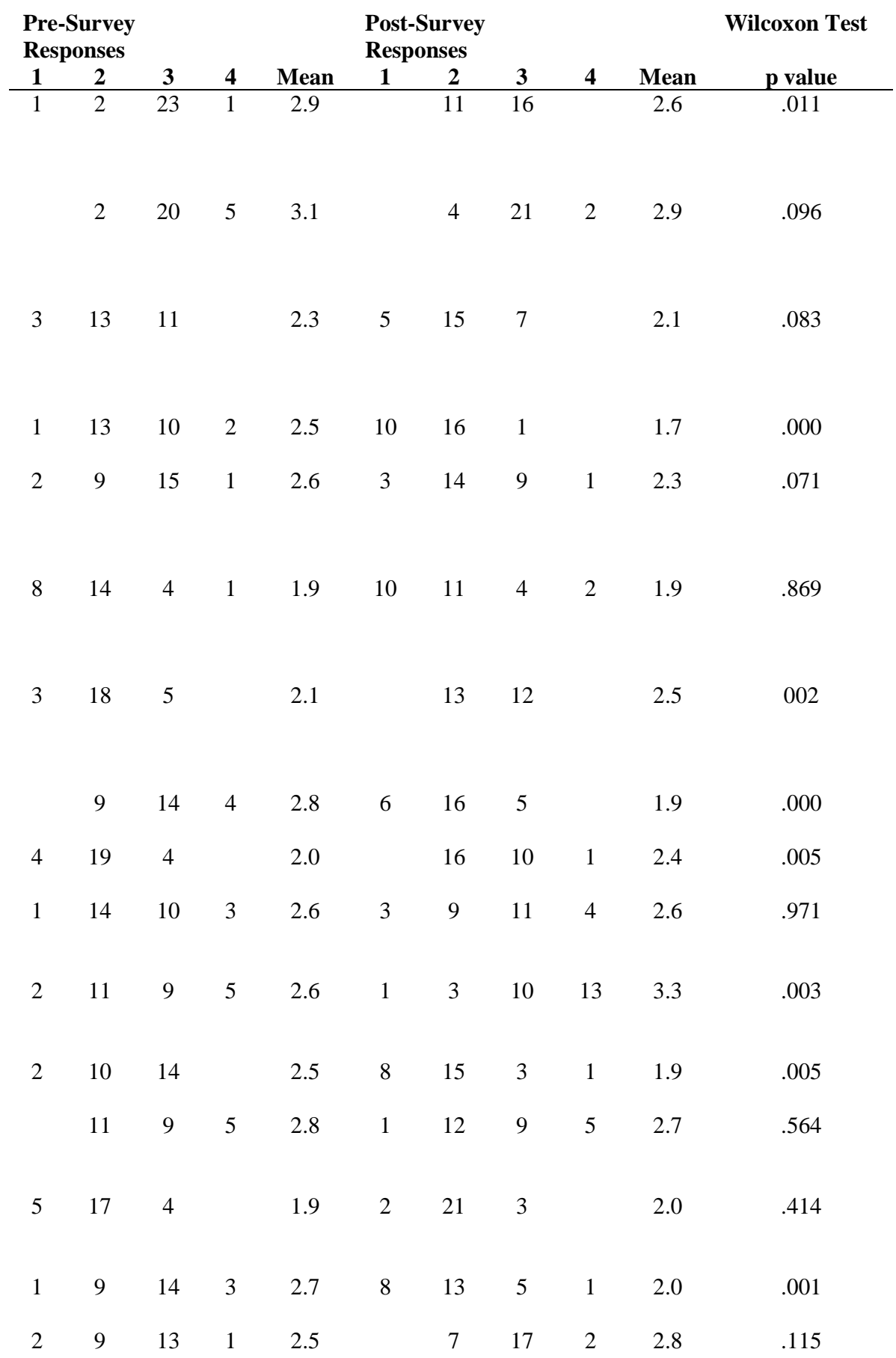


Public schools could better educate

\begin{tabular}{|c|c|c|c|c|c|c|c|c|c|c|}
\hline \multicolumn{2}{|c|}{$\begin{array}{l}\text { Pre-survey } \\
\text { Responses }\end{array}$} & \multirow[b]{2}{*}{3} & \multirow[b]{2}{*}{4} & \multicolumn{4}{|c|}{$\begin{array}{l}\text { Post-Survey } \\
\text { Responses }\end{array}$} & \multirow[b]{2}{*}{4} & \multirow[b]{2}{*}{ Mean } & \multirow{2}{*}{$\begin{array}{c}\text { Wilcoxon Test1 } \\
\text { p value }\end{array}$} \\
\hline 1 & 2 & & & Mean & 1 & 2 & 3 & & & \\
\hline 2 & 5 & 9 & 1 & 2.3 & 1 & 8 & 8 & 10 & 3.0 & .003 \\
\hline 5 & 13 & 7 & & 2.1 & & 15 & 6 & 3 & 2.5 & .004 \\
\hline 3 & 16 & 6 & 1 & 2.2 & 1 & 7 & 11 & 8 & 3.0 & .000 \\
\hline 6 & 19 & 1 & 1 & 1.9 & 15 & 10 & 2 & & 1.5 & .035 \\
\hline & 15 & 9 & 1 & 2.4 & 2 & 23 & & & 1.9 & .000 \\
\hline 1 & 17 & 7 & & 2.2 & 5 & 11 & 11 & & 2.2 & .808 \\
\hline 3 & 9 & 13 & 2 & 2.5 & 7 & 13 & 7 & & 2.0 & .015 \\
\hline & 7 & 17 & 1 & 2.5 & & 10 & 12 & 1 & 2.6 & .102 \\
\hline 4 & 15 & 7 & & 2.1 & 10 & 14 & 3 & & 1.7 & .029 \\
\hline 1 & 7 & 15 & 3 & 2.8 & 3 & 10 & 13 & & 2.4 & .042 \\
\hline
\end{tabular}
influence.

teachers' unions had less

Charter schools have higher

standards than public schools.

Teacher unions hamper educational reform.

Good teaching is well rewarded

monetarily in our current

educational system.

Charter schools do not recognize

the difference between good and

bad teachers.

Charter schools and public schools have equally high standards.

In our current system public school teachers are well rewarded in nonmonetary ways.

Too many failing charter schools remain open.

The current system of firing of public school teachers is sufficient proof that public schools are effective in regulating themselves. Charter schools are not a better alternative to public schools. 


\section{NOTES}

